DOI: $10.1515 / \mathrm{rpp}-2015-0073$

Instructor, MARIA ZAPOTICHNA

Lviv Polytechnic National University, Ukraine Address: 12 Stepan Bandera St., Lviv, 79013, Ukraine

E-mail: zapotichnam@gmail.com

\title{
TRADITIONAL EDUCATION OF ABORIGINAL PEOPLE IN CANADA: PRINCIPLES, METHODS AND CHARACTERISTIC FEATURES
}

\begin{abstract}
In the article the period of traditional education of aboriginal people in Canada in precolonial times has been presented. The main objectives have been defined as theoretical analysis of scientific and pedagogical literature, which highlights different aspects of the problem under research; characteristic of theoretical framework in understanding the concept of traditional aboriginal pedagogy and main principles underlying the education of younger generations of the indigenous people in Canada. The major components of teaching methods (practical, visual and oral) have been specified. Practical, visual and oral methods of imparting knowledge have been discussed and peculiarities of the traditional education of native population in Canada in precolonial period have been identified. The problem of traditional education of aboriginal people in Canada has been studied by scientists: aboriginal education (M. Battiste, J. Henderson, J. Lambe); development of aboriginal education (J. Friesen, V. Friesen, J. Miller, E. Neegan); tertiary education of aboriginal people (V. Kirkness); traditional education of aboriginal people (L. McGregor). The research methodology comprises theoretical methods (comparative-historical method; logical and comparative methods; methods of induction and deduction, synthesis and analysis).
\end{abstract}

Key words: traditional education, aboriginal pedagogy, Canada, indigenous people.

\section{INTRODUCTION}

Over the last decades globalization processes have not only brought the growth of the international trade, an increase in global economic integration and access to export markets but they also resulted in gradual loss of cultural identity of participating nations. Understanding that cultural uniqueness is a national asset that can significantly contribute to a nation's development, there is a growing tendency within developed countries to preserve cultural diversity of its citizens.

In 1971 Canada was the first country in the world to proclaim multiculturalism its official policy and recognize the importance of various nations that constitute uniqueness of Canadian culture. In Canadian context a special place is given to preserving aboriginal identity of the native population of the country as throughout the history federal government has implemented policies of assimilation, integration and segregation, trying to either eliminate aboriginal identity of the native people or neglect it. This has resulted in the extinction of aboriginal languages, loss of cultural traditions and overall marginalization of aboriginal population in Canadian society, causing many other social issues such as high school dropout rate, substance addiction, health problems and increasingly high unemployment rate in comparison with non-native population of Canada.

According to the latest 2011 Census, aboriginal population represents $4,3 \%$ of the total Canadian population. Taking into account anthropological characteristics, native 
population in Canada is comprised of three main groups: First Nations, Métis and Inuit people, which respectively constitute $65 \%, 30 \%$ and $4 \%$ of the total aboriginal population of Canada (Statistics Canada, 2011). Within these anthropological groups, however, there are further differences and extreme diversity. For instance, latest research has also revealed 60 existing aboriginal languages on the territory of Canada, which belong to 12 distinct language families (Statistics Canada, 2011).

At the turn of new millennium politicians, educators, policy makers and numerous community organizations throughout Canada are actively implementing various educational policies aiming at revival of aboriginal cultures and traditional aspects of their pedagogy and introducing them into educational systems of Canadian provinces and territories. In order to develop effective educational programs and implementation strategies a special consideration should be given to exploring the traditional education of the native population. The present study could be valuable for the development of educational system of Ukraine in terms of investigating traditional Ukrainian ethnic pedagogy as well as developing strategies for multicultural education in different regions of the country.

\section{THE AIM OF THE STUDY}

The aim of the article is to explore the concept of traditional education of aboriginal people in Canada. The author has defined the following objectives: to analyse the scientific and pedagogical literature, which highlights different aspects of the problem under research; to study principles underlying the system of traditional education, as well as methods used in traditional education of aboriginal peoples, and single out common characteristic features peculiar to education of native population in precolonial period.

\section{THEORETICAL FRAMEWORK AND RESEARCH METHODS}

The concept of traditional pedagogy of aboriginal people has been profoundly studied by educators all over the world, including North American scholars. "It is a growing field of inquiry, both nationally and internationally, particularly for those interested in educational innovation" (Battiste, Henderson, 2000).

Aboriginal pedagogy, which draws significantly on aboriginal knowledge, comprises the complex set of technologies developed and sustained by indigenous civilizations (Battiste, Henderson, 2000), which are different from European knowledge and existed in North America long before the arrival of the European settlers in the XVII century. According to D. Lambe, traditional education of aboriginal people is closely related to their language, culture, the territory of their residence and the experienced senior population of their community (Lambe, 2003). Therefore, traditional education of aboriginal people can be defined as a system of empirical and pedagogical knowledge, methods, principles and skills, formed by the indigenous inhabitants of Canada in the precolonial period and based on ethnocultural characteristics of aboriginal peoples that were effectively used in the process of training and educating the younger generations.

It should be noted, however, that the research of the development of the traditional pedagogy of aboriginal peoples in Canada becomes complicated, on the one hand, by the lack of any authentic written resources of the precolonial period. It is known that aboriginal people had no writing and strongly relied on oral traditions in passing their knowledge and experiences to younger generations. On the other hand, the difficulty lies in the existence of a wide diversity of tribes, which are different in terms of their cultural, social, political and linguistic characteristics. However, a thorough analysis of historical and pedagogical sources allowed us to identify some common tendencies in the traditional education of native Canadian peoples. 
For the purpose of the present study the following research methods have been employed: comparative-historical method that allowed to study scientific and pedagogical literature of the period under discussion; logical and comparative methods that have been used to trace objective regularities and similarities in the cultural diversity of numerous aboriginal tribes on the territory of Canada; methods of induction and deduction used for gathering theoretical and factual material, synthesizing and analyzing information from available resources.

\section{RESULTS}

In early aboriginal communities the concept of traditional education is closely associated with the idea of upbringing, which arises from the necessity of a man to pass on to his children his basic skills and knowledge vital for survival, including, but not limited to the desire to continue the family, preserve and nurture family traditions, imitate the parents' actions, and share one's skills and knowledge with younger generations. Therefore, in traditional aboriginal education in Canada the world was the classroom and all its members were performing the role of teachers (Friesen, 2002). The study of the traditional education of the native peoples in Canada allowed us to single out an array of principles underlying the traditional education.

Aboriginal communities had peculiar philosophical views, founded on the principle of spirituality of all things that surrounded them. "The First Peoples perceived spirits in everything, in both animate and inanimate objects, and in plants as well as in creatures of the sky, the ocean, and the earth" (Frisen, 2002). They believed that all beings have a spirit and were to live in harmony taking only what is needed for survival (McGregor, 2009). Therefore, an aboriginal person's worldview was grounded on the belief in interrelation of all the elements existing in nature. If a hunter killed an animal, he took time thanking the animal's spirit for helping him in his quest to get the food in order to continue living. The reality of interdependence and living in harmony with nature is what differentiates native peoples of Canada from Europeans who considered a man to be dominating the nature and the surrounding world (McGregor, 2009). Numerous ceremonies, religious rituals, and customs and traditions of the aboriginal peoples were founded on the concepts of spirituality, which also was the basics for their religious beliefs (Neegan, 2005).

Further studies have shown that the concept of traditional education was founded on the integrity of four aspects of a human development: spiritual, emotional, physical and mental, each one of them being no more important than the others. Maintaining the balance among these four aspects was meant to contribute to the development and learning of a person. However, when the balance was disrupted, for example, in the field of physical health, this, in turn, influenced other aspects of the development: mental - one could not quickly and correctly make decisions, emotional - could differently respond to certain events, spiritual - person felt more/ less attached to the spiritual world etc. The principle of integrity also suggested that there is no single absolute knowledge or common end-goal of education. Learning is regarded as continuous process that begins from birth and continues throughout a person's life. It includes critical thinking and the development of knowledge on mental, physical, spiritual and emotional levels, conscious ability to make mistakes and correct them. Both education and learning are focused on the process rather than the outcome of learning activities. In accordance with the traditional concept of education, children mastered knowledge in the course of their everyday life. They were taught specific knowledge, skills and values required for effective functioning in the society. Therefore, the content of training and education was teaching practical skills. 
Similarly to other ethno-cultural groups, the aboriginal people of Canada have developed their own methods of sharing knowledge with the next generations. Central to traditional education was the concept of teaching practical skills, i.e. apprenticeship, and development of the system of cultural, moral and ethical values of the community in which a child lived. The study of various historical and pedagogical sources of traditional education of aboriginal people of Canada has revealed that they have widely used practical, visual and oral methods of learning.

The practical method included teaching children practical skills by engaging them in performing daily duties of housekeeping, gathering and preserving food, making clothes, tools, etc. In this respect particular importance in the education of the younger generations was given to imitation of adults' actions, which manifested itself in the imitation of the peculiarities of performing household chores, speaking parents' language, assuming their customs, traditions and cultural rituals. Despite the similarities in the methods of sharing knowledge, there were considerable differences in practical skills that native peoples were teaching their children. These differences depended greatly on the geographical location where native population resided as well as the style of life of the native people. For example, aboriginal people of Huron tribe were teaching their children farming and agricultural techniques, Blackfoot tribe community members emphasized on sharing the knowledge of cattle rearing, whereas Inuit people in the far north were concerned with how to teach their children fishing in freezing temperatures (Friesen, 2002). One common feature of the aboriginal population of the entire North American continent was that the children were being taught from early years of their lives and that their learning, as it has already been mentioned above, was directed to mastering practical skills.

Visual methods of learning consisted primarily of the demonstration of different types of work performed by adults and observation on behalf of children. Observation played a major role due to the fact that watching their parents and helping them, children learned hunting, fishing, farming techniques, methods of cooking food, constructing houses, protecting themselves from severe weather conditions etc. (Kirkness, 1995). Both demonstration and observation broadened the children's minds and were accompanied by research methods, which emphasized the acquiring skills through practical experiences. As M. Battiste points out, the education system of the aboriginal people valued the human ability to learn independently through observation, listening and participation, with a minimum adult intervention or instruction (Battiste, 2000).

Oral methods of training and education manifested themselves in the explanations, stories and conversations of adults and children and played an essential role in the system of traditional education of aboriginal people. A distinct characteristic feature of traditional pedagogy of aboriginal people was that the system of moral and ethical values and basic norms of conduct was taught to children by means of indirect, non-coercive methods and based on instructive stories - legends. The study of historical and pedagogical sources has revealed that it was unacceptable to use physical punishment in the process of educating children. Instead, native people have widely relied on conversations and indirect means of pointing to a child's inappropriate behaviour or wrongdoings. For instance, one of the common practices in case of disobedience was to make a child feel ashamed by telling a legend. D. Miller in his book "Shingwauk's Vision: A History of Native Residential Schools" discusses one of such legends. A couple of boys, who were laughing at an old woman and humiliated her, turned into a constellation. Every time children were looking at the night sky adults would be reminding them of this legend, teaching them to respect an 
elderly people of the community (Miller, 1997). One of the most interesting features of educational legends was that they were adjusted to particular time and place, depending on the morale to be taught. Very often there would be numerous versions of the same legend that would have common beginning, but then each version would digress and would be changed to suit the narrator (Friesen, 2002).

The fact of absence of any written forms and strong reliance on oral practices in educating children has led to singling out one more feature of the traditional education of the aboriginal people of Canada - importance of language and mother tongue in native cultures. The scholars and researchers of historical and pedagogical issues of native people in Canada claim that their languages were extremely rich and contained far more concepts and realis than any other languages in the world. Together with native traditions, customs and folklore, language was the central means of educating younger generations over the centuries, the very means of self-identification and development of the nations until the European discovery of the continent. Therefore, preservation of the native language was crucial for survival and progressive development of these nations.

\section{CONCLUSIONS}

Traditional education of aboriginal people of Canada refers to the system of empirical knowledge and practical principles, methods and skills widely used for educating younger generations before arrival of the first European settlers. Although the aboriginal population of Canada was extremely diverse in terms of languages, cultures, styles of living, geographical locations and skills that have been taught to children, a thorough analysis allowed us to single out a couple of common characteristic features.

The study of education in early traditional settings of aboriginal peoples of Canada has revealed that they have been accumulating knowledge through life experiences in the process of various activities and everyday life situations. Due to this fact educational institutions did not exist, learning process was not structured and traditional education of the aboriginal peoples of Canada was informal.

Further analysis of traditional education of native people in Canada has shown that education strongly relied on the principles of spirituality, integrity, religiousness and nature. The concept of traditional education was founded on four closely interrelated elements of spiritual, emotional, physical and mental aspects of a person's development, each one being of equal importance and value. Education was regarded as continuous learning process, which began in early years and lasted through a person's life and included practical, visual and oral methods of learning.

Common characteristic features of traditional education of native population in Canada in precolonial period was strong reliance on oral traditions, importance of language and cultural background as the fundamental elements for survival and sustainable development of the communities.

Further study of the traditional education of aboriginal people in Canada we consider perspective.

\section{REFERENCES}

1. Battiste, M., Henderson, J. (2000). Protecting Aboriginal Knowledge and Heritage: A Global Challenge. Saskatoon : Purich Press, 69 p.

2. Friesen, J., Friesen, V. (2002). Aboriginal Education in Canada: A Plea for Integration. Calgary : Detselig Enterprises, Ltd., 168 p. 
3. Kirkness, V. (1995). Aboriginal Peoples and Tertiary Education in Canada: Institutional Responses. The London Journal of Canadian Studies, Volume 11, pp. 28-40.

4. Lambe, J. (2003). Aboriginal Education, Mainstream Education, and Native Studies. The American Indian Quaterly, Volume 27, No 1, 2, pp. 308-324.

5. McGregor, L. (2009). Ontario First Nations Perspectives on Traditional Knowledge: a diagnostic and Discussion Paper. Toronto, Ont : Ciefs of Ontario, 35 p.

6. Miller, J. (1997). Shingwauk's Vision: A History of Native Residential Schools. Toronto : University of Toronto Press, $254 \mathrm{p}$.

7. Neegan, E. (2005). Excuse me: Who Are the First Peoples of Canada? A Historical Analysis of Aboriginal Education Then and Now. International Journal of Inclusive Education, Volume 9, No 1, January-March, pp. 3-15.

8. Statistics Canada. (2011). Aboriginal Peoples in Canada: First Nations People, metis, and Inuit. Retrieved 20.11.2015 from : http://www12.statcan.gc.ca/nhs-enm/2011/assa/99-011-x/99-011-x2011001-eng.cfm. 